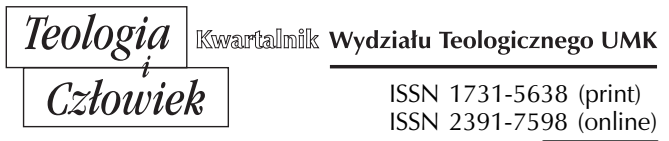

\title{
NAUCZANIE RELIGII W KULTURZE CYFROWEJ
}

DOI: http://dx.doi.org/10.12775/TiCz.2021.014

Streszczenie. Artykuł Nauczanie religii $w$ kulturze cyfrowej jest ujęciem syntetycznym, podzielonym na trzy zasadnicze części. W pierwszej scharakteryzowano kulturę nazywaną w Dyrektorium o katechizacji (2020) „kulturą cyfrową”, która wywiera bardzo duży wpływ na zmiany w komunikacji i życiu współczesnych ludzi, także na zmiany w edukacji religijnej. Technologie informacyjno-komunikacyjne mają wiele zalet, nie są jednak pozbawione niebezpieczeństw, dlatego stawiają przed katechetami nowe zadania, które opisano w drugiej części. W ostatniej części wskazano na możliwość prowadzenia edukacji medialnej dzieci i młodzieży szkoły podstawowej na lekcjach religii w korelacji $\mathrm{z}$ innymi przedmiotami, przede wszystkim w zakresie wychowania uczniów do odpowiedzialnego korzystania z nowych technologii.

\footnotetext{
Abstract. Teaching Religious Education in the Digital Culture. The article offers a synthetic approach to the subject and is divided into three main parts. The first part characterizes the culture that is referred to in the Directory for Catechesis (2020) as "digital culture" and has a major impact on transformations in communication and in the lives of modern people as well as on changes in Religious Education. While information and communications technologies have many advantages, they also come with certain dangers. Therefore, they present teachers of Religious Education with new tasks as described in the second part of the article. The final part indicates that it is possible to conduct media education of primary school students during classes of Religious Education in correlation with other school subjects. This suggestion focuses, in particular, on educating children and young people on how to use new technologies in a responsible manner.
} 
Słowa kluczowe: Dyrektorium o katechizacji; kultura cyfrowa; nauczanie religii; katechizacja; korelacja międzyprzedmiotowa.

Keywords: Directory for Catechesis; digital culture; teaching Religious Education; catechesis; correlation between subjects.

Internet, net, sieć, „cyfrowy kontynent” ${ }^{1}$ to wyrażenia oznaczające cyberprzestrzeń, która nieustannie się rozwija i coraz bardziej przenika wszystkie aspekty ludzkiego życia. Towarzyszące temu nowe zjawiska wpływają na zmianę filozofii kształcenia i wymagają podejmowania nowych zadań, także w zakresie edukacji religijnej. Przykładem jest prowadzenie lekcji online w czasie pandemii COVID-19 i wykorzystanie Internetu w niespotykanym dotąd zakresie. Dla wielu nauczycieli religii taka forma prowadzenia zajęć była niemałym wyzwaniem. Część z nich nie korzystała wcześniej z technologii informacyjno-komunikacyjnej, nie posiadała żadnych lub przynajmniej elementarnych kompetencji cyfrowych. Zagadnienie wykorzystania cyberprzestrzeni dla celów katechetycznych było nierzadko pomijane nie tylko w praktyce szkolnej, lecz także w dokumentach katechetycznych Kościoła katolickiego. Problematyka nowych technologii i możliwość ich wykorzystania w działalności katechetycznej podjęta została po raz pierwszy w Dyrektorium o katechizacji wydanym w $2020 \mathrm{r}$.

Celem niniejszego opracowania, $\mathrm{z}$ konieczności ograniczonego do kilku stron wymaganiami wydawcy, jest przedstawienie zagadnienia kultury cyfrowej i jej wpływu na nauczanie religii w ujęciu Dyrektorium o katechizacji. Problem badawczy precyzują dwa pytania: Jakie zadania powinny być realizowane na szkolnych lekcjach religii w czasach kultury cyfrowej? oraz W jakim zakresie nauczanie religii może wspierać szkołę w przekazywaniu uczniom kompetencji medialnych? Kwerenda zasobów internetowych wykazała, że tak sformułowany problem nie doczekał się jeszcze publikacji ${ }^{2}$.

1 Zob. Benedykt XVI, Orędzie na XLIII Światowy Dzień Środków Społecznego Przekazu, Watykan 4 I 2009.

2 Znane nam jest opracowanie: D. Fołtyn, Środowisko cyfrowe jako naturalny obszar funkcjonowania współczesnego człowieka w świetle Dyrektorium o katechizacji, „Zeszyty Formacji Katechetów" 1 (2021), s. 39-46; https://www.zfk.katecheza.radom.pl/index.php/zfk/article/view/1321/774 (data dostępu: 23.09.2021). 
Poszukując odpowiedzi na sformułowane wyżej pytania posłużono się techniką krytycznej analizy materiałów źródłowych, do których należą Dyrektorium o katechizacji (2020), Program nauczania religii rzymskokatolickiej w przedszkolach i szkołach (2018), Rozporządzenie Ministra Edukacji Narodowej z dnia 14 lutego 2017 r. w sprawie podstawy programowej, a także syntezą w celu sformułowania końcowych wniosków.

Niniejsze opracowanie jest ujęciem syntetycznym, ukierunkowanym na trzy zagadnienia. W pierwszej części scharakteryzowano współczesną kulturę nazywaną w Dyrektorium o katechizacji kulturą cyfrową, która wywiera bardzo duży wpływ na zmiany w komunikacji i życiu ludzi, także na zmiany w edukacji religijnej. Technologie informacyjno-komunikacyjne mają bez wątpienia wiele zalet, nie są jednak pozbawione niebezpieczeństw, dlatego stawiają przed katechetami nowe zadania, które opisano w drugiej części. W ostatniej wskazano na możliwość prowadzenia edukacji medialnej dzieci i młodzieży szkoły podstawowej na lekcjach religii $\mathrm{w}$ korelacji $\mathrm{z}$ innymi przedmiotami, przede wszystkim $\mathrm{w}$ zakresie wychowania uczniów do odpowiedzialnego korzystania z nowych technologii. Całość wieńczy krótkie zakończenie.

\section{OGÓLNA CHARAKTERYSTYKA KULTURY CYFROWEJ W DYREKTORIUM O KATECHIZACJI}

Nowe dyrektorium jest pierwszym dokumentem katechetycznym, w którym podjęto refleksję na temat istotnych założeń dotyczących przekazu wiary w kontekście wyzwań, który stawia świat cyfrowy i globalizacja kultury. Zatwierdzone przez papieża Franciszka w dniu 23 marca 2020 roku Dyrektorium o katechizacji ${ }^{3}$ jest nie tylko ponad 200-stronnicową książką uaktualniającą poprzednie Dyrektorium ogólne o katechizacji (1997), ale dokumentem, który w wielu kwestiach wprowadza novum. Po raz pierwszy dyrektorium zostało przygotowane przez Papieską Radę ds. Krzewienia Nowej Ewangelizacji, a nie jak poprzednio przez Kongregację ds. Duchowieństwa, co wyraża bardziej „jednoznacznie misyjny

3 Papieska Rada ds. Krzewienia Nowej Ewangelizacji, Dyrektorium o katechizacji, Watykan 2020, wyd. pol. Kielce 2020 [dalej skrót: DoK]. 
charakter nowego dokumentu"4. Bez wątpienia istotną nowością jest także podjęcie przez autorów refleksji na temat kultury cyfrowej i jej wpływu na katechizację oraz wychowanie młodego pokolenia. Dokument ten - zdaniem Rino Fisichella - ma być pierwszą próbą odpowiedzi na nową kulturę cyfrową, w której bardzo szybko zmienia się czas i miejsce. To z kolei implikuje potrzebę lepszego kontaktu z kulturą ludzi młodych, którzy urodzili się w świecie cyfrowym, a także uwzględnienia tego w ich formacji i wychowaniu ${ }^{5}$.

Charakteryzując współczesną kulturę, dyrektorium podkreśla jej „cyfrowość, która przenika cały świat i jest nie tylko „częścią dotychczasowych kultur, ale narzuca się jako nowa kultura zmieniająca przede wszystkim język, kształtująca mentalność i ustawiająca nową hierarchię wartości" (DoK 359). Jest to proces powszechny, globalny, cyfrowe urządzenia służące do komunikacji znoszą odległości geograficzne i bariery między ludźmi. Nowe technologie wpływają nie tylko na poważne zmiany w komunikacji i życiu ludzi, ale wywołują także istotne zmiany kulturowe. Autorzy dokumentu zauważają, że wytworzyła się nowa „infrastruktura kultury”. Dla wielu przestrzeń wirtualna staje się ważniejsza od realnego świata. W tej przestrzeni pozyskuje się wiadomości i informacje, wypracowuje i wyraża opinie, bierze udział w dyskusjach, rozmawia i szuka odpowiedzi na różne pytania (por. DoK 213).

Dostrzegając pozytywne aspekty Internetu i sieci społecznościowych, dyrektorium wskazuje na „cyfrowe wzmocnienie”, które daje m.in. możliwość dialogu między ludźmi na całym świecie, dostępu do wiedzy i informacji, „obiegu niezależnych informacji”, poszerzania i wzmacniania poznawczych zdolności człowieka (por. DoK 360).

Środowisko cyfrowe jest obszarem także wielu zagrożeń. Dokument wymienia je, powołując się na adhortację papieża Franciszka Christus vivit (2019, nr 88-89). Mowa jest o zagrożeniach, na które wskazywał wcześniej także Jan Paweł II w Orędziu na XXXVI Światowy Dzień

${ }^{4}$ K. Bronk, Nowe dyrektorium o katechizacji: więcej ewangelizacji, https://www. vaticannews.va/pl/watykan/news/2020-06/dyrektorium-o-katechizacji.html [data dostępu: 5.09.2021].

5 Por. tamże.

${ }^{6}$ Zob. J. Bednarek, A. Andrzejewska (red.), Zagrożenia cyberprzestrzeni i świata wirtualnego, Warszawa 2014. 
Środków Społecznego Przekazu Internet: nowe forum głoszenia Ewangelii (2002) oraz dokument Papieskiej Rady ds. Środków Społecznego Przekazu Kościół a Internet (2002) 7 , m.in. samotność w Sieci, przemoc i pornografia, uzależnienie od Internetu, izolacja i utrata kontaktu z rzeczywistością. W odniesieniu do zagrożeń środowiska cyfrowego $\mathrm{w}$ dyrektorium użyty został, niewystępujący dotąd w dokumentach katechetycznych, termin dark web $b^{8}$. Dokument wskazuje również na „ogromne interesy ekonomiczne" obecne w świecie cyfrowym, które manipulują sumieniami ludzi; niektóre platformy, które stanowią „zamknięte obiegi” rozpowszechniania fałszywych informacji, podsycają uprzedzenia i nienawiść. Cyfrowa przestrzeń może poprzez kreowanie wypaczonej wizji rzeczywistości prowadzić do zaniechania dbałości o życie wewnętrze (por. DoK 361), co dla duchowego rozwoju człowieka jest szczególnie niebezpieczne.

Dyrektorium podkreśla wpływ kultury cyfrowej na religijność ludzi ${ }^{9}$ „Kultura cyfrowa jawi się jako zbiór przekonań, mających cechy religijne" (DoK 365). Zjawisko, którego jesteśmy świadkami zmienia, $\mathrm{w}$ procesie obdarzania zaufaniem i autorytetem, cały układ odniesienia. Współczesny człowiek poprzez kierowanie do algorytmów sztucznej inteligencji lub komputera pytań z zakresu życia prywatnego, wchodzi w relację z maszyną i „od niej w postawie zaufania oczekuje odpowiedzi”. W ten sposób „tworzy się swego rodzaju uniwersalna pseudoreligia, która legitymuje nowe źródło autorytetu i posiada wszystkie elementy obrzędu religijnego" takie, jak: ofiara, bojaźń absolutu, poddanie nowej sile sprawczej, „która każe się kochać, lecz sama nie kocha” (DoK 366).

7 Zob. B. Bilicka, Katecheza wobec zagrożeń Internetu, w: Wychowanie do wartości w świecie cyberkultury, red. B. Bilicka, Toruń 2012, s. 149-167.

8 „Darknet, czy też Dark Web to zbiorcza nazwa, którą nadano ciemnej stronie Internetu. Tworzą go przede wszystkim anonimowe fora dyskusyjne, strony internetowe, sklepy e-commerce oraz blogi. Od tradycyjnych serwisów odróżnia je między innymi to, że nie znajdziecie ich w ogólnodostępnych wyszukiwarkach internetowych, ani po bezpośrednim wpisaniu ich adresów w przeglądarce To prawdziwe internetowe podziemie, do którego nie każdy ma dostęp", B. Charzyński, Czym jest DarkNet i jak do niego wejść? Zbiór informacji o ciemniej stronie Internetu, https://scroll.morele.net/poradniki/czym-jest-dark-net-i-jak-do-niego-wejsc/ [data dostępu: 16.09.2021].

${ }_{9}$ Więcej na ten temat: K. Kaźmierska, Młodzi w Kościele. Złe wieści, https://misyjne.pl/mlodzi-w-kosciele-zle-wiesci-statystyki/?fbclid=IwAR1Bidw0KRZEIcbPHEnV uoYHIslJhfUd7cbsMOlTklzB0zs7rlaUjEGTQPY [data dostępu: 16.09.2021]. 
Autorzy dokumentu przestrzegają przed możliwością utworzenia globalnej kultury mającej wpływ na sposób myślenia i wiarę kolejnych pokoleń, które będą coraz bardziej cyfrowe. Na współczesne zmiany kulturowe wpływają m.in. różne platformy komunikacyjne posiadające potencjał błyskawicznego przekazu i zasięgu działania. Rodzi to nie tylko wyzwanie, lecz także daje szansę do prowadzenia działalności duszpasterskiej o zasięgu globalnym, „tak jak globalna jest kultura cyfrowa”. Trzeba jednak wypracować nowatorskie sposoby ewangelizacji, znaleźć odpowiednie narzędzia i formy, które „byłyby w stanie odkodować przesłanki antropologiczne leżące u podstaw tego zjawiska" (DoK 367). Postulat ten odnosi się także do katechezy, ma ona nieustannie szukać skutecznego sposobu przekazu wiary, który powinien być dialogiem, a nie tylko jednokierunkową komunikacją nauczyciel-uczeń.

\section{ZADANIA KATECHEZY WOBEC WYZWAŃ KULTURY CYFROWEJ}

Kultura cyfrowa i postępująca w coraz większym tempie cyfryzacja komunikacji i społeczeństwa prowadzi do istotnej przemiany antropologicznej. Korzystając z terminologii, której autorem jest Marc Prensky ${ }^{10}$, dyrektorium rozróżnia wśród użytkowników Internetu cyfrowych tubylców (digital native) i cyfrowych imigrantów (digiral immigrants). Do pierwszych zalicza uczniów, osoby urodzone w świecie cyfrowym; do drugiej wychowawców, nauczycieli, katechetów, którzy nierzadko urodzili się przed epoką cyfrową. Między tymi dwiema grupami panuje duża różnica nie tylko w podejściu do nowych technologii i ich wykorzystania, lecz także w sposobie komunikacji, w stylu wypowiedzi. Język cyfrowych tubylców jest bardziej spontaniczny, interaktywny i partycypacyjny, aniżeli digital immigrants (por. DoK 362).

Młodzi ludzie przedkładają raczej obraz nad słuchanie. Ich język jest w pewien sposób ukształtowany przez „konsumpcję medialną”, która prowadzi u niektórych do ograniczenia umiejętności krytycznego myślenia. „Konsumowanie cyfrowych treści” generuje zarówno nowy język

10 Zob. M. Prensky, Digital Natives, Digital Immigrants, „On the Horizon” 9 (2001) 5, https://marcprensky.com/writing/Prensky\%20-\%20Digital\%20Natives,\%20Digital\%20 Immigrants\%20-\%20Part1.pdf [data dostępu: 16.09.2021]. 
komunikacji, jak i „nowy sposób organizacji myślowej”, który charakteryzuje wielozadaniowość, hipertekstualność oraz interaktywność, wyższość zdolności intuicyjnych i emocjonalnych nad analitycznymi. Młodzież woli język opowieści aniżeli argumentacji. „Sztuka snucia opowieści (storytelling), stosująca zasady retoryki i własny, przejęty od marketingu, język, uznawana jest przez młodych ludzi za bardziej przekonującą i angażującą formę przekazu niż tradycyjne formy dyskursu" (DoK 363). Z trudem korzystają ze słowa pisanego, jeżeli nie jest ono uzupełnione dźwiękiem i obrazem (por. DoK 214).

W tym miejscu należy zwróci uwagę na wspomniany w dyrektorium storytelling. Jest to sztuka opowiadania, budowania narracji, snucia ciekawych opowieści. Wykorzystuje się ją m.in. we współczesnym marketingu, a także w edukacji, w celu sfabularyzowania przekazu i zaciekawienia nim uczniów. Szczególne znaczenie w pracy z młodzieżą mają cyfrowe opowieści (digital storytelling) jako sposób prowadzenia narracji z wykorzystaniem treści cyfrowych. Zdaniem Daniela Makusa pomagają one uczniom lepiej zrozumieć i wyrażać siebie, komunikować swoje potrzeby i problemy, sprzyjają autorefleksji, motywują do rozwiązywania problemów indywidualnych oraz danej społeczności, pozwalają lepiej zrozumieć innych, rozwijają empatię i tolerancję, są skutecznym narzędziem edukacyjnym, które angażuje uczniów we własny proces uczenia się. Tego typu opowieści mogą być stosowane na każdym przedmiocie $\mathrm{w}$ formie pracy domowej lub na spotkaniach koła zainteresowań ${ }^{11}$. Zagadnienie digital storytelling nie jest jednak znane nauczycielom religii. Nie znajdziemy go w refleksji polskich katechetyków. Nie jest nam znany podręcznik dydaktyki religii, w którym problematyka ta zostałoby omówiona.

Sposób komunikacji cyfrowych tubylców, do których zalicza się na świecie znaczna część dzieci, jest dużym wyzwaniem dla nauczycieli religii, tym bardziej że nie znamy jeszcze wszystkich jego konsekwencji. Z pewnością jednak komunikacja ta prowadzi do zmian w zakresie poznawczym i racjonalnym, a także wpływa „w jakiś sposób na naturalną skłonność do doświadczenia religijnego" (DoK 237). Można postawić pytanie, w jaki sposób mówić do katechizowanych żyjących w kulturze cy-

11 Por. D. Makus, Cyfrowe opowieści z iPadem, iBooks, s. 2, https://itunes.apple. $\mathrm{com} / \mathrm{pl} /$ book/cyfrowe-opowie\%C5\%9Bci-z-ipadem/id741341355?l=pl\&mt=11 [data dostępu: 23.09.2021]. 
frowej, aby uwzględniając ich potrzeby, przekazać prawdy wiary w sposób zrozumiały i skuteczny? Kościół głosi je od 2000 lat i jak podkreślają autorzy dokumentu, głosi w sposób jednokierunkowy - naucza i przedstawia istotę dogmatów (por. DoK 214). Taki sposób przekazu nie jest jednak językiem, którym posługują się digital native. Bardziej otwarte na interakcję, której oczekują cyfrowi tubylcy, są cyfrowe formy komunikacji, z których Kościół powinien w odpowiedni sposób korzystać. Potrzebna jest obecność chrześcijan w Internecie ${ }^{12}$, aby dać świadectwo wartości ewangelicznych (por. DoK 214), także w serwisach społecznościowych, które mogą być narzędziem ewangelizacji oraz czynnikiem rozwoju człowieka (por. DoK 215). Wykorzystanie rzeczywistości wirtualnej do ewangelizacji, nie może oczywiście w żaden sposób zastąpić bezpośredniego spotkania osób w realnym świecie, zwłaszcza rzeczywistości duchowej, sakramentalnej i eklezjalnej. Zaawansowane technologie są potrzebne dla „aktualnej i znaczącej obecności” Kościoła w świecie, w czasach kultury cyfrowej. Jednakże istotnym problem jest nie tyle zaopatrzenie się w nowoczesne narzędzia, co autentyczna komunikacja będąca owocem rzeczywistej interakcji między ludźmi w celu dawania świadectwa Ewangelii (por. DoK 217).

Zadaniem katechezy jest doprowadzić katechizowanych do osobowej relacji z Jezusem, ale ta relacja przez cyfrowych tubylców nie zawsze może być właściwie rozumiana. Dlatego należy wyjaśnić uczniom język, którym posługują się internauci. Jest to język posiadający często znamiona języka religijnego, aczkolwiek nie może być z nim utożsamiany. Dyrektorium podkreśla konieczność wyjaśnienia uczniom, co to znaczy być uczniem Jezusa i że relacja z Nim nie jest relacją, jaką nawiązuje się pomiędzy influencerem a jego wirtualnym followersami. Uczniowie Jezusa potrzebują przewodników obdarzonych autorytetem, ludzi, którzy poprzez świadectwo wiary i towarzyszenie młodym pomogą im odkryć własne życiowe powołanie (por. DoK 370).

Lekcja religii nie może się po prostu „ucyfrowić”. Katecheci powinni korzystać z nowoczesnych technologii, nie zapominając jednak o potrzebie tworzenia przestrzeni do przeżywania doświadczenia wiary, które przemienia człowieka i daje klucz do interpretacji życia w perspektywie

12 Zob. B. Bilicka, Chrześcijański styl obecności na „cyfrowym kontynencie” w orędziach Benedykta XVI, „Forum Teologiczne” 16 (2015), s. 139-151. 
Bożego planu zbawienia ludzi. Na katechezie należy wyjaśnić zagadnienia sensu życia, cielesności i tożsamości płciowej człowieka, uczuciowości, sprawiedliwości i pokoju, które w epoce cyfrowej często są interpretowane w odmienny sposób (por. DoK 371).

Katecheza musi prowadzić młodych $\mathrm{z}$,samotniczego świata społecznościowego" do wspólnoty Kościoła, w której doświadczenie Boga prowadzi do komunii z Nim i ludźmi. Należy na nowo odkryć możliwości liturgii i sztuki sakralnej, miejsc wyrażających tajemnicę wiary. Potrzebna jest „inkulturacja cyfrowego świata”. Należy młodym ludziom pomóc rozwijać się w Sieci jako podmiot, a nie jako przedmiot, „wykraczać poza samą tylko technikę i w ten sposób, w relacji z Chrystusem, odnajdywać odnowione człowieczeństwo" (DoK 372).

\section{EDUKACJA MEDIALNA NA LEKCJACH RELIGII JAKO ELEMENT KORELACJI MIĘDZYPRZEDMIOTOWEJ}

Nauczyciele religii muszą podjąć nowe wyzwanie kulturowe, które stoi przed nimi w epoce cyfrowej, stosować w swojej pracy narzędzia, które są powszechnie używane w dydaktyce i które bardziej „przystają” do młodego pokolenia. Priorytetem staje się wychowanie cyfrowych tubylców do umiejętnego korzystania $\mathrm{z}$ tych narzędzi i odróżniania aspektów pozytywnych od problematycznych. Współcześni katecheci muszą być świadomi, że świat wirtualny ma głęboki wpływ na jego użytkowników, przede wszystkim najmłodszych i osoby szczególnie wrażliwe, a także może powodować trudności w radzeniu sobie z emocjami oraz zaburzać proces budowania tożsamości (por. DoK 216). Obecni adresaci szkolnej katechezy to młodzi ludzie, którzy potrafią korzystać z technologii cyfrowej w różnych obszarach codziennego życia, ale nie potrafią analizować i właściwie oceniać, zjawisk zachodzących w Internecie. Autorzy dyrektorium podkreślają, że młode pokolenie nie zawsze jest dobrze przygotowane do zmierzenia się z wyzwaniami społeczeństwa cyfrowego. Mamy „swego rodzaju cyfrowy analfabetyzm”, który wymaga pilnej edukacji medialnej. Współczesnymi analfabetami są ci, „którzy nie potrafią rozróżnić, pod względem jakości i prawdziwości, rozmaitych treści cyfrowych, na jakie napotykają" (DoK 368). 
Edukacja medialna dzieci i młodzieży, którą Dyrektorium o katechizacji nazywa "pilną" to bez wątpienia bardzo ważne zadanie systemu oświaty. Szkoła ma obowiązek stworzyć uczniom warunki do nabywania wiedzy i umiejętności nie tylko z zakresu informatyki, posługiwania się komputerem i urządzeniami cyfrowymi, ale także „przygotowywać ich do dokonywania świadomych i odpowiedzialnych wyborów w trakcie korzystania z zasobów dostępnych w Internecie, krytycznej analizy informacji, bezpiecznego poruszania się w przestrzeni cyfrowej, w tym nawiązywania i utrzymywania opartych na wzajemnym szacunku relacji z innymi użytkownikami sieci"13. Analizując Podstawę kształcenia ogólnego $(2017)^{14}$, widzimy, że edukacja medialna jest realizowana od najmłodszych lat, w klasach I-III w ramach edukacji przyrodniczej, informatycznej i w kształceniu językowym. W drugim etapie edukacyjnym obejmującym klasy IV-VIII zagadnienia związane $\mathrm{z}$ nowymi technologiami są obecne w kształceniu językowym, muzyce, wiedzy o społeczeństwie, przyrodzie, geografii, biologii, informatyce, wychowaniu fizycznym, wychowaniu do życia w rodzinie.

Przygotowanie młodego pokolenia do zmierzenia się z wyzwaniami społeczeństwa cyfrowego to zadanie, które powinno być realizowane na wszystkich przedmiotach szkolnych, także na lekcjach religii. Analizując Program nauczania religii rzymskokatolickiej $w$ przedszkolach i szkołach (2018), w zakresie wskazań dla szkoły podstawowej dostrzegamy, że zagadnienie nowych technologii informacyjno-komunikacyjnych obecne jest w klasach V-VIII ${ }^{15}$. Istotnym elementem programu są wskazania do korelacji religii z edukacją szkolną. Autorzy wymieniają trzy przedmioty: plastykę, wychowanie do życia w rodzinie, wiedzę o społeczeństwie. W klasie VII w zakresie korelacji z plastyką sugerują „wykonanie pracy plastycznej na temat Dekalogu - tworzenie artystycznych projektów edukacyjnych o charakterze interdyscyplinarnym (również z wyko-

13 Rozporządzenie Ministra Edukacji Narodowej z dnia 14 lutego 2017 r. w sprawie podstawy programowej, Dz.U. z dnia 24 II 2017 r., poz. 356.

14 Ze względu na syntetyczne ujęcie naszego artykułu ograniczamy analizę Podstawy kształcenia ogólnego (2017) oraz Programu nauczania religii (2018) do szkoły podstawowej. Analiza podjętego przez nas zagadnienia w kontekście szkoły średniej wymaga odrębnego opracowania.

15 Zob. Konferencja Wychowania Katolickiego Konferencji Episkopatu Polski, Program nauczania religii rzymskokatolickiej $w$ przedszkolach i szkołach, Częstochowa 2018, s. 103, 117, 136, 154. 
rzystaniem technologii informacyjno-komunikacyjnych)"16, a w korelacji z wychowaniem do życia $\mathrm{w}$ rodzinie wskazują na potrzebę omówienia zagadnienia pornografii i cyberseksu ${ }^{17}$. Z kolei w klasie VIII, w korelacji $\mathrm{z}$ wiedzą o społeczeństwie należy na lekcjach religii podjąć problematykę korzyści i zagrożeń wynikających z korzystania z Internetu, przemocy $\mathrm{w}$ cyberprzestrzeni oraz odpowiedniej na nią reakcji ${ }^{18}$.

Szkolne nauczanie religii nie tylko może, ale i powinno wspierać szkołę w przekazywaniu uczniom kompetencji medialnych. Nie chodzi o naukę posługiwania się urządzeniami cyfrowymi i wiedzę z zakresu informatyki, ale o wychowanie uczniów do odpowiedzialnego i etycznego korzystania z nowych technologii. Należy wskazać na zagadnienia, które naszym zdaniem powinny być przedmiotem refleksji na lekcjach religii m.in: przelotność oraz ulotność informacji w Internecie, ich etyczna ocena i krytyczna selekcja; możliwość użycia Sieci w celach złych i szkodliwych; zasady etyczne obowiązujące w Internecie, np. Dekalog internau$t y^{19}$; sprzeciw wobec hejtu, np. 10 przykazań pozytywnego internauty ${ }^{20}$; zasady etycznego korzystania z komputera i komunikacji elektronicznej ${ }^{21}$.

\section{WNIOSKl}

Z przeprowadzonej analizy wybranych fragmentów Dyrektorium o katechizacji można wyciągnąć istotne dla praktyki katechetycznej wnioski:

1. Katecheza jest jedną z podstawowych form posługi słowa w Kościele, a język katechetyczny jednym z czynników wpływających na rozwój wiary wychowanków i ich osobowej więzi z Bogiem² ${ }^{22}$.

16 Tamże, s. 126.

17 Por. tamże, s. 128.

18 Por. tamże, s. 139, 146.

19 Zob. J. Kloch, Dekalog internauty, „Więź” 8-9 (2002), s. 86.

20 Zob. B. Kwiatkowski, 10 przykazań pozytywnego internauty, https://biuroprasowe.orange.pl/blog/10-przykazan-pozytywnego-internauty/ [data dostępu: 20.09.2021].

${ }^{21}$ Zob. http://wolamielecka.pl/51-wiara/wiara/118-dekalog-internauty [data dostępu: 20.09.2021].

${ }^{22}$ Por. H. Iwaniuk, Język katechetyczny, w: Wokót katechezy posoborowej, red. R. Chałupniak, J. Kochel, J. Kostorz, W. Spyra, Opole 2004, s. 130. 
Język katechezy stanowi przedmiot badań naukowych ${ }^{23}$, brakuje jednak pogłębionej refleksji na temat współczesnego języka katechezy, która uwzględniałaby zjawisko kultury cyfrowej mającej istotny wpływ na sposób komunikowania się cyfrowych tubylców. Impulsem do badań powinny być zalecenia zawarte w nowym dyrektorium, które podkreśla „dostosowanie katechezy młodych, polegające na przełożeniu przesłania Jezusa na ich język" (DoK 245).

2. Język, który trafia do digital native, to język opowieści, a nie argumentacji, którą bardzo często stosuje się na katechezie. Potrzebne są badania na temat możliwości wykorzystania digital storytelling w katechezie, czy i w jakim stopniu można cyfrowe opowieści wykorzystać także na lekcji religii?

3. Należy zwrócić uwagę, aby w komunikacji na lekcjach religii dominował dialog, a nie jednokierunkowa komunikacja katecheta-katechizowany. Potrzeba jest większego słuchania uczniów, rozmowy z nimi, większej otwartości na ich potrzeby, a nie prowadzenie lekcji metodami podającymi.

4. Pokolenie cyfrowe posługuje się językiem bardziej interaktywnym i spontanicznym, aniżeli katecheci. Nie chodzi jednak o zamianę wykładu na pogadankę czy papierowej książki na jej wersję elektroniczną. Należy docenić i wykorzystać kreatywność uczniów, ich umiejętności w posługiwaniu się urządzeniami cyfrowymi i nowymi technologiami do ewangelicznego świadectwa na „cyfrowym kontynencie”. Naszym zdaniem dobrym rozwiązaniem jest wykorzystanie na lekcjach religii m.in. modelu $\mathrm{SAMR}^{24}$ i praca metodą projektu $\mathrm{z}$ wykorzystaniem nowych technologii.

5. Elementy edukacji medialnej należy wprowadzić na lekcje religii w klasach I-III szkoły podstawowej.

23 Zob. K. Misiaszek, Próba poszukiwania zasad używania języka w katechezie: https://opoka.org.pl/biblioteka/T/TA/TAK/km_jezykzasady.html [data dostępu: 20.09.2021]; R. Przybylska, W. Przyczyna (red.), Język katechezy, Tarnów 2008.

24 Zob. B. Bilicka, M. Gurzyński, iPad na szkolnych lekcjach religii, Toruń 2019, s. $13-32$. 


\section{BIBLIOGRAFIA}

Bednarek J., Andrzejewska A. (red.), Zagrożenia cyberprzestrzeni i świata wirtualnego, Warszawa 2014.

Benedykt XVI, Orędzie na XLIII Światowy Dzień Środków Społecznego Przekazu, Watykan 4 I 2009.

Bilicka B., Katecheza wobec zagrożeń Internetu, w: Wychowanie do wartości w świecie cyberkultury, red. B. Bilicka, Toruń 2012, s. 149-167.

Bilicka B., Chrześcijański styl obecności na „cyfrowym kontynencie” w orędziach Benedykta XVI, „Forum Teologiczne” 16 (2015), s. 139-151.

Bilicka B., Gurzyński M., iPad na szkolnych lekcjach religii, Toruń 2019.

Bronk K., Nowe dyrektorium o katechizacji: więcej ewangelizacji, https://www.vaticannews.va/pl/watykan/news/2020-06/dyrektorium-o-katechizacji.html.

Charzyński B., Czym jest DarkNet i jak do niego wejść? Zbiór informacji o ciemniej stronie Internetu, https://scroll.morele.net/poradniki/czym-jest-dark-net-i-jak-doniego-wejsc/.

Iwaniuk H., Język katechetyczny, w: Wokół katechezy posoborowej, red. R. Chałupniak, J. Kochel, J. Kostorz, W. Spyra, Opole 2004, s. 130-132.

Fołtyn D., Środowisko cyfrowe jako naturalny obszar funkcjonowania współczesnego człowieka w świetle Dyrektorium o katechizacji, „Zeszyty Formacji Katechetów” 1 (2021), s. 39-46, https://www.zfk.katecheza.radom.pl/index.php/zfk/article/ view/1321/774.

Kaźmierska K., Młodzi w Kościele. Złe wieści, https://misyjne.pl/mlodzi-w-kosciele-zle-wiesci-statystyki/?fbclid=IwAR1Bidw0KRZEIcbPHEnVuoYHIslJhfUd7cbsMOlTklzB0zs7rlaUjEGTQPY.

Kloch J., Dekalog internauty, „Więź” 8-9 (2002), s. 86.

Konferencja Wychowania Katolickiego Konferencji Episkopatu Polski, Program nauczania religii rzymskokatolickiej w przedszkolach i szkołach, Częstochowa 2018.

Kwiatkowski B., 10 przykazań pozytywnego internauty, https://biuroprasowe.orange.pl/ blog/10-przykazan-pozytywnego-internauty/.

Makus D., Cyfrowe opowieści z iPadem, iBooks, https://itunes.apple.com/pl/book/cyfrowe-opowie\%C5\%9Bci-z-ipadem/id741341355?l=pl\&mt=11.

Misiaszek K., Próba poszukiwania zasad używania języka w katechezie: https://opoka.org. pl/biblioteka/T/TA/TAK/km_jezykzasady.html.

Papieska Rada ds. Krzewienia Nowej Ewangelizacji, Dyrektorium o katechizacji, Watykan 2020, wyd. pol. Kielce 2020.

Prensky M., Digital Natives, Digital Immigrants, „On the Horizon” 9 (2001) 5.

Przybylska R., Przyczyna W. (red.), Język katechezy, Tarnów 2008.

Rozporządzenie Ministra Edukacji Narodowej z dnia 14 lutego 2017 r. w sprawie podstawy programowej, Dz.U. z dnia 24 II 2017 r., poz. 356. 